University at Albany, State University of New York

Scholars Archive

\title{
Reading for Idea Advancement in a Grade 4 Knowledge Building Community
}

Jianwei Zhang

University at Albany, State University of New York, jzhang1@albany.edu

Follow this and additional works at: https://scholarsarchive.library.albany.edu/etap_fac_scholar

Part of the Education Commons

\section{Recommended Citation}

Zhang, Jianwei, "Reading for Idea Advancement in a Grade 4 Knowledge Building Community" (2011). Educational Theory and Practice Faculty Scholarship. 7.

https://scholarsarchive.library.albany.edu/etap_fac_scholar/7

This Article is brought to you for free and open access by the Educational Theory and Practice at Scholars Archive. It has been accepted for inclusion in Educational Theory and Practice Faculty Scholarship by an authorized administrator of Scholars Archive. For more information, please contact scholarsarchive@albany.edu. 


\title{
To appear in Instructional Science
}

Running Head: Reading for Idea Advancement

Reading for Idea Advancement in a Grade 4 Knowledge Building Community

\author{
Jianwei Zhang \\ Yanqing Sun
}

University at Albany, State University of New York

\section{Correspondence:}

Jianwei Zhang

Department of Educational Theory and Practice

University at Albany

1400 Washington Ave, ED 115B

Albany, NY 12222 USA

Phone: (518) 442-4007; Fax: (518) 442-5008

Email: jzhang1@albany.edu 


\begin{abstract}
This study looks into the reading practice in a Grade 4 knowledge building community that involved 22 students and a veteran teacher. The students investigated light over a threemonth period supported by Knowledge Forum, a networked collaborative knowledge-building environment. The classroom designs encouraged the students to take on high-level responsibility for advancing the community's knowledge, as represented in their online discourse in Knowledge Forum. The tracing of student conversations in Knowledge Forum and content analysis of their portfolio notes demonstrate productive advancement of scientific understanding. Qualitative analyses of classroom videos, online discourse, and the teacher's reflection journal characterize student reading practice along four themes: reading for the purpose of advancing community knowledge; as progressive problem solving; embedded in sustained knowledge-building discourse; and as dialogues between local understanding and knowledge in the larger world. These results contribute to elaborating the possibility and processes of integrating reading with creative knowledge work in content areas. Classroom strategies are identified and discussed in relation to the role of collaborative online technologies.
\end{abstract}

Keywords: Reading in content areas, Knowledge building community, Scientific inquiry, Collaborative learning, Reading to learn. 
Reading for Idea Advancement in a Grade 4 Knowledge Building Community

\section{Introduction}

Education in a knowledge-based society needs to develop students' creative knowledge capabilities and high-level literacy. Existing literature suggests the possibility of achieving these two educational goals through an integrated process that engages students in authentic literacy practices as a part of their learning across subject areas (Applebee 1981; Bereiter \& Scardamalia 1987a; Cantoni-Harvey 1987; Connolly \& Vilardi 1989; Guthrie, 2004; Sun, Zhang, Scardamalia, 2010). Such integration entails an expanded and functional view of language as a means to disciplinary thinking, discourse, and inquiry (Cervetti, Pearson, Bravo, \& Barberp, 2006; Phillips \& Norris, 2009; Vitale \& Romance, 2007). It further requires research on the specific classroom processes and instructional support that can help students deal with the broadly reported difficulties associated with deep processing of expository text (Graesser, 2007; Phillips \& Norris, 1999) and student-driven inquiry (Krajcik, Blumenfeld, Marx, Bass, \& Fredricks, 1998). Contributing to elaborating the possibility and processes of integrating reading with creative knowledge work in content areas, the present study investigates student reading practice in an elementary science classroom that implements the knowledge building pedagogy and technology (Scardamalia \& Bereiter, 2006). It characterizes reading as a deep and collaborative engagement integral to creative knowledge work, with the specific analyses shedding light on the classroom processes and scaffolding strategies.

\section{$\underline{\text { Research on Reading in Content Areas }}$}

Cognitive research interprets reading as a constructive process. Reading is not simply to 
retrieve information from text; but a "process of constructing meaning through the dynamic interaction among the reader's existing knowledge, the information suggested by the written language, and the context of the reading situation.” (Wixson \& Peters, 1984, p. 5) Proficient readers use effective strategies to actively interact with the text they are reading, connect the text with their goals and prior knowledge, connect information across the text, monitor their understanding and identify gaps and questions, and engage in inferential construction of meaning and explanation (Anderson, 1984; Graesser, 2007; Wittrock, 1991). Recent sociocognitive perspectives additionally underline dialogic interaction surrounding text and joint exploration of ideas (Olson, 1997; Palincsar, 2003). Comprehension of difficult text can be significantly enhanced through extended, open-ended, interactive conversations focused on authentic problems related to the text, interconnecting reading, writing, discussion, and inquiry (Applebee, Langer, Nystrand, \& Gamoran, 2003; Beck, Mckeown, Hamilton, \& Kucan, 1997; Chinn, Anderson, \& Waggoner, 2001; Nystrand, 1997).

In line with the advances of reading theories and learning research more broadly, research on reading in content areas (e.g., science) has evolved from an individual to a sociocognitive and sociocultural perspective. Earlier studies on reading to learn and learning from text mostly focused on individual interaction with a single text to examine reading processes, strategies, reader characteristics, and text features that lead to effective comprehension and learning (e.g., Anderson \& Armbruster, 1984; Collins, 1994; Denise, 1987; Goldman, 1997; Kiewra, DuBois, Christensen, Kim, \& Lindberg, 1989). Important connections and overlaps were identified between cognitive and metacognitive strategies of reading and science process skills (e.g., classifying, predicting, inferring, relating, evaluating, communicating), converging at fostering independent readers and learners (Baker, 1991; Padilla, Muth, \& Padilla, 1991). 
These earlier research on reading in science and other content areas was most conducted with the use of contrived text, with little knowledge developed regarding reading in the context of naturally occurring science learning (Palincsar \& Magnusson, 2001).

Although investigating effective strategies to support individual processes of reading to comprehend and learn continues to be an important research theme, recent studies give more emphasis to social interactions surrounding the text that lead to appropriation of reading strategies, group inquiry, and peer sharing and teaching of new knowledge. The interactive and collaborative approaches involve individual comprehending and learning and further situate it in social and authentic contexts to enable productive disciplinary knowledge construction and literacy development.

Several research-based instructional programs have emerged to foster student reading and use of text in the service of collaborative disciplinary inquiry. The most well-known is perhaps Reciprocal Teaching, which engages a student group in dialogues to jointly construct and monitor their understanding of the text. Reading strategies, such as questioning, clarification, summary, and predicting, become integral elements of the group's conversation (Palincsar \& Brown, 1984). Although originally designed to foster comprehension among challenging readers, Reciprocal Teaching has been applied and extended to supporting collaborative inquiry in subject areas, particularly under a fostering community of learners framework (Brown \& Campione, 1996). Members in a small group take turns to lead discussions of articles or multimedia materials as a part of their inquiry. Different small groups develop expertise related to different topics, then conduct cross-talks to teach each other new information and provide mutual comprehension checks (Brown \& Campione, 1996). The subsequent work of Palincsar and colleagues further elaborated the interplay 
between activity-based, firsthand and text-based, secondhand investigations in science classrooms. This interplay is enhanced through a guided inquiry framework composed of steps such as engaging (e.g., defining questions), investigating, explaining, and reporting. Students are encouraged to construct and use a new genre of text modeled on a scientist's notebook (e.g., presenting purpose, questions, procedures, claims) to support their reasoning, leading to positive outcomes (Palincsar \& Magnusson, 2001).

Similar to fostering community of learners (Brown \& Campione, 1996), Anderson and colleagues (1997) created the WEE Science program that organizes an inquiry project as three phases: Wondering, Exploring, and Explaining. Students work as special interest groups to browse books about scientific topics and generate wonderment issues, which are further refined into researchable questions. They then explore these questions through building models, conducting observations and experiments, and further reading. In the last phase, they summarize their insights and further wonderments and share their findings with peers through presentations.

As another example, Concept-Oriented Reading Instruction (CORI) was developed to integrate reading strategy instruction and inquiry science in a mutually supportive way (Guthrie, 2004). CORI is based on the notion that "important, interesting conceptual themes are a valuable context for teaching comprehension strategies and for sustaining the motivation required for long-term reading development." (Guthrie, 2004, p. 6) Focusing on a scientific theme (e.g., birds around the world), students engage in several phases of reading and inquiry. They first conduct field observations, generate personal questions, and decide on favorite questions and sub-themes to focus on. Then, they gather information from text and other media and conduct observations and experiments to answer their personal questions. 
Information from multiple sources is then integrated and summarized and further exchanged in small groups. In the final phase, students write reports and make presentations to communicate their findings and teach peers and other audiences (Perencevich, 2004).

Integrating insights gained from the above programs, Cervetti and colleagues (2006) recently developed the Seeds of Science/Roots of Reading ${ }^{\mathrm{TM}}$ program that capitalizes on potential synergies between science and literacy. Their program particularly focuses on developing key meaning-making strategies that are important for both scientific inquiry and literacy, such as making prediction, posing questions, making explanations from evidence, searching for information in text, engaging in discourse, summarizing, writing reflections, and so forth.

$\underline{\text { Reading for Idea Advancement in a Creative Community }}$

The above-reviewed research efforts to integrate literacy and disciplinary inquiry (especially in science) have been largely driven by a vision to engage students in authentic literacy and inquiry practices that mirror the practices of real-world knowledge communities, such as those of scientists (Anderson et al., 1997; Cervetti et al., 2006; Palincsar \& Magnusson, 2001). Reading is a goal-directed (Graesser, 2007) and socially situated practice (Olson, 1997; Palincsar, 2003). People in everyday life use literacy as a sense-making tool to solve practical problems, cope with personal changes, and understand and gain control over their environment (Barton \& Hamilton, 1998). In the context of creative knowledge communities, reading serves as an integral means to enabling intentional, sustained, and collaborative idea advancement. This social context and the high-order goal of knowledge creation have a deep impact on why, when, what, and how to read. Reading becomes an inquiry process (Phillips \& Norris, 2009) that serves the goal of collaborative knowledge 
advancement. As Yore and colleagues (2004) highlighted, "scientists rely on printed text for ideas that inform their work before, during, and after the experimental inquiries." (p. 348) In a survey by Tenopir and King (2004), the participant scientists rated reading as essential to their research and as a primary source of creative stimulation. They reported spending 553 hours per year or $23 \%$ or their work time on reading, in addition to $35 \%$ of their work time on writing, speaking, and other communicating activities. Scientists seldom read an article section by section for complete comprehension like what students do in their reading classes (Geisler, 1994). Instead, they identify and scan articles that are highly relevant to their research and selectively focus on parts of the articles that may help them to gain new insights and new methods of doing research. They contextualize and critically examine how the reported research was designed and implemented (Geisler, 1994), and make connections and analogies to the research conducted in their own labs to inform idea development (Dunbar, 1997). They also read important progress from outside their main disciplines in search of far connections of ideas that can lead to creative advancement (Simonton, 2003). Information and ideas obtained from readings further become objects of discourse in lab meetings, discussions, and informal exchanges (Latour \& Woolgar, 1979) and are further cited in academic writing for accumulative knowledge advancement.

Such reading practices that are required by creative and collaborative knowledge work are rarely the focus of current teaching practices in Language Arts and science classrooms. Reading in science classrooms has been generally focusing on student understanding of isolated technical terms and factual information (Phillips \& Norris, 2009). In parallel, student writing and oral discourse tend to lack idea-centered reasoning, explanation, and argument (Ebbers \& Rowell, 2002; Newton \& Newton, 2000). Addressing this practice gap requires a 
better understanding of what it means and takes for students to engage in reading for collaborative advancement of ideas in science and other content areas (c.f. Palincsar \& Magnusson, 2001). The above-reviewed programs (Anderson et al., 1997; Cervetti et al., 2006; Guthrie, 2004; Palincsar \& Magnusson, 2001) played a pioneer role in exploring how reading for collaborative advancement of ideas can be enabled across content areas. However, the designs of these programs at this point are often based upon a speculative understanding of reading practice contributive to creative knowledge advancement, heightening the need of empirical studies based on rich data collections in real classroom contexts (Cervetti et al., 2006). Moreover, inquiry practices in these programs are sequenced as fixed stages such as questioning, reading, experiment, and presentation, as pre-scripted by the designer or teacher. Further research needs to examine reading and inquiry in more complex and open-ended contexts where students take on high-level agency in managing the unfolding classroom flow.

\section{Reading Practice in Knowledge Building Communities}

The present study examines student reading and inquiry practice in a knowledge building community (Scardamalia \& Bereiter, 2006). Knowledge building represents one of the few sophisticated pedagogical models to engage students in collaborative and creative work with knowledge and ideas and develop high-order competencies needed in the Knowledge Age. The primary goal of a knowledge building community is to continually advance the state of the community's knowledge, as a social product (Bereiter, 2002), in line with knowledge creation practices in innovative organizations that rely on sustained advancement of knowledge and knowledge-based products to survive and grow (Nonaka \& Takeuchi, 1995; Sawyer, 2007). This pursuit of community knowledge as a social product differentiates a knowledge building community from many collaborative inquiry classrooms that focus on 
collaborative processes but individual learning outcomes, such as mental models and cognitive strategies residing in individual minds (see also, Stahl, 2006). The programs to integrate reading and disciplinary inquiry (Anderson et al., 1997; Cervetti et al., 2006; Guthrie, 2004) share such a focus on collaborative processes but individual outcomes: Students develop understanding about different aspects of an inquiry topic and then share with peers through presentations to diffuse the knowledge to more individuals. The process of knowledge building unfolds as continual idea improvement and progressive chains of problem solving, with deeper challenges progressively identified and addressed as understanding deepens (Bereiter, 2002; Hatano \& Inagaki, 1986). This process differs from the procedures adopted by many inquiry classrooms that are focused on finding answers to pre-designed problems by searching and integrating information from multiple sources, following a stagebased inquiry script (e.g., Perencevich, 2004). In a knowledge building community, students contribute ideas to a community space, critically examine the diverse ideas, and engage in sustained progressive discourse to revise, combine, reorganize, synthesize, and reconceptualize their ideas for increasing explanatory power, coherence, and utility. The knowledge building process is further advanced through Knowledge Forum ${ }^{\circledR}$, a collaborative online environment rooted in the research on writing, expertise, and knowledge building (see Scardamalia \& Bereiter, 2006). Lying at the heart of Knowledge Forum is a shared, multimedia knowledge space that gives student ideas a public representation—as conceptual objects - along with a set of interaction tools to support knowledge-building discourse.

Continually advancing and adding value to the knowledge of a community through sustained idea improvement is essential to real-world knowledge building communities (e.g., a science community, a high-tech corporate) and the knowledge economy at large (Sawyer, 
2007). In such contexts of knowledge creation, high-level literacy — extended idea-centered dialogues, knowledge-transforming writing, deep listening, productive reading, multiple modes of idea representation — becomes a primary means to participating in communal knowledge practices (Bereiter \& Scardamalia, 2005; Latour \& Woolgar, 1979; Sawyer, 2007; Yore, Hand, \& Prain, 2002). As noted previously, their reading practice is not merely for comprehending the text or integrating information from multiple sources as the answers to personal questions; but serves the need to understand and continually advance the state of knowledge in a domain and leverage sustained discourse and idea development (Csikszentmihalyi, 1999).

Investigating student literacy engagement in a knowledge building community represents an important research opportunity to inform classroom processes for developing high-level literacy that is contributive to creative knowledge work (c.f., Lankshear \& Knobel, 2003; Palincsar \& Ladewski, 2006). Several studies have been conducted along this line, showing that students in knowledge building classrooms exhibit significant gains in literacy (Scardamalia, Bereiter, Brett, Burtis, Calhoun, \& Smith-Lea, 1992) and take a more goaldirected and constructive approach to using text (Scardamalia, Bereiter, Hewitt, \& Webb, 1996). A recent study analyzed the online knowledge-building discourse of a class of students over two years - Grades 3 and then 4-and demonstrated significant growth of productive written vocabulary, including sophisticate academic words and technical words that are hard to be appropriated at these grade levels. Constructive and extensive use of text—along with sustained knowledge-building discourse, online and offline — was identified as an important avenue of vocabulary appropriation and development, which further leverages collaborative knowledge building (Sun, Zhang, Scardamalia, 2010). 
The present study further examines reading practice in a Grade 4 knowledge building community facilitated by a veteran teacher. The research goal is twofold: (a) to characterize and elaborate reading practices that are integral and contributive to sustained knowledge building in a community, and (b) to identify major support strategies used by the teacher to enable productive reading and knowledge building. Addressing these issues through rich data collection helps to advance our understanding of reading integral to creative knowledge work and inform classroom processes to foster it.

\section{Method}

\section{$\underline{\text { Participants }}$}

The participants were a class of 22 fourth-graders (9-to-10-year-olds) at the Institute of Child Study Laboratory School in Toronto. This study analyzes their inquiry of light conducted over a three-month period, supported by Knowledge Forum. The students had been using Knowledge Forum to conduct knowledge building since Grade 1. The teacher had strong expertise in facilitating knowledge building, as indicated through a prior study that analyzed his improvement of knowledge building designs over three years leading to productive collaboration and sophisticated scientific understanding among his students (Zhang et al., 2009).

Knowledge Building Design and Implementation

The optics inquiry was conducted in line with the principles of knowledge building (Scardamalia, 2002). Particularly, the knowledge building design encouraged students' epistemic agency in high-order decision-making related to knowledge goals, long-range planning, and progress evaluation. Instead of having their teacher pre-specify the inquiry goals, tasks/questions, procedures, timeline, and grouping, the students took on collective 
responsibility for co-constructing and refining problems of understanding, inquiry strategies, participatory structures, and online discourse spaces. One of the knowledge building principles highlights constructive use of authoritative sources for idea improvement. To address their deepening problems related to light, the students found and used a large amount of reading materials, many of which were written for students above Grade 4. To deal with the difficult texts, they formed into temporary small groups to cooperatively understand the texts, summarize new meanings and implications, and generate further ideas and questions.

Thus, the knowledge building unfolded as an emergent, dynamic process that involved multiple forms of inquiry activities, online and offline. Students generated problems of understanding, discussed diverse ideas and theories through face-to-face knowledge-building discourse, conducted self-generated experiments and observations, searched libraries and the Internet, and comprehended new resources through cooperative reading. They contributed problems, ideas, data, and resources (generated through face-to-face discourse, reading, experiments, etc.,) into Knowledge Forum for continual dialogues and improvement of ideas. Knowledge Forum provided the public knowledge space in which student ideas and inquiry work were recorded, in views (workspaces) corresponding to their focal goals. Figure 1 shows student discourse in the Lenses and Sight view. By writing notes in these views, the students contributed their ideas, data, and related information using text and graphics. Supportive features for knowledge-building discourse allowed the students to co-author, build on, and annotate notes; create reference links with citations to existing notes; add keywords; and create rise-above notes to summarize, distil, and advance their discussions (Scardamalia, 2004). The students accessed Knowledge Forum through six desktop computers in the classroom. Flexible arrangements were made so that they could write and read notes based on 
emergent needs, either individually or in small groups. Several whole class sessions were arranged in a computer lab where each student worked on a computer to read and write notes.

Insert Figure 1 about here

The light inquiry began with a whole class conversation that reviewed the students' online discussion about animal adaptation when they were in Grade 1 that had been archived in Knowledge Forum. The issue of how white fur reflects and dark fur absorbs light stimulated refreshed interest. Light was therefore identified as a focal area of study for the current school year. A new view was created in Knowledge Forum, called "Grey Fur and White Snow." As the inquiry proceeded, questions related to new focal themes were progressively identified, leading to the creation of six additional views in Knowledge Forum (e.g., Lenses and Sight, Mirrors, Reflection and Absorption) in line with the emergent goals. $\underline{\text { Data Sources and Analyses }}$

To gauge the productivity of the students' knowledge building, we analyzed their collaborative discourse in Knowledge Forum (68 pages in print) and individual portfolio notes (36 pages, single space). Focusing on the growth of the community's knowledge space, we traced student online discourse in the seven views to identify deepening questions and ideas and, then, compared the questions and ideas against the curriculum guidelines. Individual knowledge growth was further measured based on student portfolio notes. Each student created three portfolio notes in Knowledge Forum that summarized their optical understanding in the first, second, and third month of the inquiry, respectively. Following content analysis (Chi, 1997), student writing related to each inquiry theme (e.g. how are 
rainbows created) was coded using two four-point scales that had been tested in our previous studies (see Sun et al., 2010 for details): (a) scientific sophistication (1 - pre-scientific, 2 hybrid, 3 - basically scientific, and 4 - scientific) and (b) epistemic complexity (1 unelaborated facts, 2 - elaborated facts, 3 - unelaborated explanations, and 4 - elaborated explanations). Epistemic complexity measures student effort to produce not only descriptions of the material world but theoretical explanations of hidden mechanisms (Salmon, 1984). Two raters independently coded 12 portfolio notes to assess inter-rater reliability: Cohen's Kappa $=.83$ for scientific sophistication, Cohen's Kappa $=.75$ for epistemic complexity.

To characterize student reading practice and understand the teacher's role, we used a grounded theory approach (Strauss \& Corbin, 1998) to analyze three interrelated sets of data: (a) Videos of selected classroom sessions (about six hours) representing a wide range of activities, including whole class conversations, small group reading, experiments, and computer-based sessions; (d) Online discourse records in Knowledge Forum; and (c) The teacher's reflection journal (14 pages) that recorded his design ideas and plans, classroom processes, and reflections. The above data were comprehensively analyzed to understand the interactional processes that sustained the productive knowledge building in the community (see Zhang \& Messina, 2010). The analyses presented in this article focus on the central phenomenon of reading.

Investigating reading practice in authentic social contexts entails a broader focus beyond the moment when a reader is directly facing the text, so as to capture the readers' thinking and practices that lead to, co-occur with, and emerge from the immediate reading activities. With this focus in mind, we analyzed the data to understand in what contexts the need to read emerged, how the material met the readers, how personal inquiry foci and roles were 
negotiated, how the students interacted surrounding the text, as well as how the reading information was used in the subsequent conversations and inquiry. Our analysis integrated multiple levels and timescales (Lemke, 2000), shifting from higher to lower focal levels as we moved towards more detailed analysis. Specifically, we first analyzed the three-month inquiry, as a whole, to understand how it started and evolved, leading to an understanding of the conceptual lines of inquiry and the related major episodes of classroom videos and online discussions. We then analyzed each video episode to understand its context and storyline, including the conceptual focus, activities, social structures, and progress of understanding. At the lowest level, we identified and coded patterns of discourse moves in the video episodes (e.g., introducing information from a reading, asking a challenging question, contributing an idea addressing a peer's question) through an emergent inductive process without applying a predefined coding scheme (Sawyer, 2006). We additionally analyzed the online discourse focusing on the nature of contribution made by each entry (i.e., note), as indicated through the scaffold labels (think types) used in the notes such as: My theory, New information (from reading), I need to understand, and so forth (see the opened note in Figure 1). For the purpose of this study, all codes related to reading were pooled together in search of substantive connections, leading to the inductive aggregation of the codes into fewer more encompassing themes representing important facets of reading practice in the knowledge building community. The initial themes were then refined, elaborated, and validated through theme to theme, theme to data, data to data comparison.

\section{Results}

In the light inquiry, a total of 168 notes (excluding the 66 portfolio notes) were contributed to the seven views in Knowledge Forum, with each student authoring 8.45 notes 
on average. In each view, the students identified deeper questions, contributed ideas, and examined the ideas using data, leading to progress of understanding. Deeper challenges were further identified by the students as the understanding deepened. For example, in the view of "Colors of Light and Rainbows," the students progressively examined how rainbows are created, why the colors are always in the same order, primary and secondary colors, and how we see colors. The student discourse addressed all the concepts expected for Grade 4 in the Ontario Curriculum as well as many issues expected for Grades 6 and 8, such as light waves, color vision, concave and convex lenses, the law of reflection, and so forth. Individual knowledge advancement was assessed through the content analysis of student portfolio notes. Repeated measures ANOVAs indicated significant growth of the students' optical understanding across the three months as rated based on epistemic complexity $(\underline{F}(2,42)=$ 69.20, $\underline{\mathrm{p}}<.001$, partial $\left.\underline{\eta}^{2}=.77\right)$ and scientific sophistication $(\underline{\mathrm{F}}(2,42)=70.60, \underline{\mathrm{p}}<.001$, partial $\left.\underline{\eta}^{2}=.77\right)$ (see detailed report in Zhang \& Messina, 2010).

Analysis of the classroom videos, online discourse, and the teacher's reflection journal using a grounded theory approach helped to characterize student reading along four themes, which are elaborated below.

\section{Reading for the Purpose of Advancing Community Knowledge}

In addition to using reading as a means to answering personal questions and addressing individual learning needs, reading in the knowledge building community became a social and community action to address collective knowledge goals. The students collaboratively defined and evolved their specific knowledge goals related to understanding light, which were represented using a list of questions (e.g., how shadows work, how lenses work, how are rainbows created). New views were created in Knowledge Forum corresponding to the 
emergent knowledge goals. The students monitored progress and gaps in their communal knowledge space. Identification of gaps and weak areas led to individual and collaborative actions to advance understanding, with reading as an important means.

For instance, through a whole class conversation, the community identified major inquiry goals and represented the goals using a list of focal problems. Among the problems was how plants adapt to light. Two weeks later, a student searched the Knowledge Forum database where the collective knowledge and work is represented, but found no contribution addressing this problem. He mentioned this knowledge gap to the community and the teacher, leading to the following conversation and further actions of reading and inquiry.

$\mathrm{T}$ (Teacher): ... Now, what are the questions that people asked originally...? [One] was "do plants adapt to light?" ... But somebody did a search and he or she could not get any notes about that. ... Was that you [looking at a student]? See, this is from a Grade 9 book, something called "Plants React to Light." It's interesting, and this really nice diagram [pointing to a page]. Would anyone be interested in doing a [cooperative reading] around that?

S1: Oh, I would.

T: Who would like to join S1? ... Remember we need titles, [keywords] for a paragraph, and you underline [key information]... Quite interesting here, it talks about water and oxygen and carbon dioxide and simple sugars food plants making...

S2: I'll read that.

T: Would you be interested in doing that? OK, maybe the two of you could go together. 
The two students volunteered to form into a temporary group to read the book about how plants react to light. They engaged in discussions to make sense of the text and develop ideas to address the aforementioned knowledge gap. They then co-authored a note in Knowledge Forum to share the key ideas with the community (Figure 2).

Insert Figure 2 about here

In the above example, the teacher highlighted a knowledge gap of the community that had been originally identified by a student (i.e., no note addressing how plants adapt to light). To enable further inquiry addressing this gap, he found and brought in relevant reading material, connected the material to existing student work and ideas, and highlighted key points of the material as an advanced organizer (“Quite interesting here, it talks about...”). He, then, invited students to form into a cooperative group to co-understand the difficult text, and reminded and modeled reading strategies they might use (e.g., keywords, underlining). New information obtained through the reading was synthesized and contributed to the Knowledge Forum database for continual discussion and idea development, helping to bridge reading, writing, and face-to-face and online discussions.

The teacher explicitly designed his class in light the principle of collective responsibility for knowledge advancement (Scardamalia, 2002; Zhang et al., 2009). He engaged his students in metacognitive discussions about how they could advance the knowledge of the community instead of only individual learning. The students found and read materials that could address the community's needs and might not directly relate to the questions they were personally researching. As the teacher said in the beginning of a whole class conversation: 
$\mathrm{T}:$... Normally students would go and ask for a reading or get a reading to answer a question that that student was researching. On Friday you didn't do that. On Friday, we just sort of said: Yeah, I'd like to read about that or I'd like to read about that, maybe not even answering your specific question but answering someone else's question that we got from the [Knowledge Forum] database. [inaudible] getting new information and not even realizing that the new information was gonna be helpful to you specifically, but you knew it might be helpful to someone in our community here. So that was great.

\section{Reading as Progressive Problem Solving}

The reading practice integrated in knowledge building went far beyond comprehending what was presented in the text to involve sustained chains of progressive problem solving, with deeper challenges and problems identified as their understanding advanced (Bereiter, 2002). This process of progressive problem solving led to deeper interpretation and analysis of the text, student-generated experiments and observations, and extended dialogues.

For instance, in a video episode, two girls and a boy worked as a small group to read a book chapter about refraction of light. They designed an experiment based on what they had read: They used a glass jar half filled with water, put a rod in the jar and adjusted its position, observed the rod from different angles, and talked about their observations. They frequently went back to the book to revisit related information. Each student had a notebook on the desk and frequently took notes in it. Their observation confirmed the scientific principle presented in the book about light refraction and also led them to identifying a puzzling issue to be better understood: The rod looked bent when observed from aside, but did not look so bent when observed from above. The book did not tell anything about such difference, which caused live 
discussions in this small group. One of the students called the teacher, who was working with another group, to join them. The teacher was fascinated by the students' problem of understanding, about which he did not have a ready answer. He quickly browsed what the students had read and observed the rod from different angles and, then, co-analyzed the experiment with the students.

$\mathrm{T}$ [holding up the water jar, observing while talking]: It also happens in here. It also seems to be happening in here, look. Does it look bent? Well, we're trying to read why that happens... Let's offer some theories before we read this... Why do we think it looks bent when we look at it in the water?

[Students gave a few ideas]

T: Look what it [the book] says here. [Reading the text] "This is a glass rod... It seems to be made of separate parts." [Pointing to a figure in the book] Part 1, 2 and 3. [Continuing reading the text] "This happens because light hits different parts of the rod." So look at this [sentence]. "Light from different parts of the rod passes through...[inaudible] the combination." [Pointing to different part of the rod in the figure] What is this passing through? So what is the light that's hitting that passing through?

S1: The glass.

T: Glass? Only glass here, here? And what? And from here? ... So here it says: "Light from different parts of the rod passes through different combinations of water, glass and air. Each time it moves from one substance to another, it is bent." Students over talking: Oh, oh! ... 
The teacher and the students then co-analyzed what the light reflected from the rod passes through when they observed from different angles to understand why the rod looked bent in different ways. Their conversation further extended the principle of light refraction to explaining why convex lenses concentrate light, followed by productive discourse in the classroom and online in Knowledge Forum. The two seemingly different phenomena—rod bending and lens concentrating — were connected up through the underlying principle.

In another example, the students were interested in how rainbows are made. Through reading related texts and conducting experiments with prisms, they realized that rainbows in the sky are created by raindrops acting like prisms that split white light into different colors. A question was then asked: why are the colors in rainbows always in the same order? This question led to extended discussions that resulted in further insight in the connection between color order in rainbows and a seemingly different topic —-wavelength of light—about which several students had read a book chapter several weeks before.

As the literature suggests, when using books as sources in inquiry learning, students often treat information from books as the authoritative answer. Productive knowledge building requires students to view and use sources in the same way that scientists do: to identify useful ideas that can be drawn upon and come up with unanswered questions and challenges (Collins, 1998). In both examples shown above, the students did not simply find and comprehend the text as the answer, but constantly monitored their new understanding and identified what needed to be further understood. Such constructive processing of text went beyond the classroom sessions when the students were directly interacting with the text and was further embedded in the sustained chains of inquiry over multiple weeks or even months, leading to increasingly elaborated and complicated understanding. 


\section{Reading Embedded in Knowledge-Building Discourse}

The students' productive use of text for progressive problem solving was often actualized and augmented through their collaborative knowledge-building discourse: idea-centered discourse that led to not only sharing of information but transformation of knowledge and continual refinement of ideas. Such discourse occurred during small group reading, which further triggered whole class conversations and extended discourse, online and offline. Ideas, information, and terms from text were collaboratively processed and revisited and further used as conceptual tools to leverage extended conversation and conceptual advancement, woven into the unfolding intellectual history of the community.

The deepening inquiry of light led the students to finding and reading many materials, including those written for students of higher grade levels. Small-group cooperative reading was used as a strategy to help students comprehend difficult text. The aforementioned group reading and experiment on light bending provides a specific example. Members in a group coread a text, discussed problems that the text might address, underlined and summarized key information, and figured out what it meant to their work in relation to the problems and ideas the community had been working on. To deepen and examine their understanding, they often co-designed and conducted experiments and observations side by side with their reading/rereading of the text.

New thoughts developed through individual and group reading often led to improvisational whole-class conversations. New ideas were shared and further examined, interpreted, and refined, with deeper challenges identified informing further inquiry. For example, on a morning in the classroom, the students were working in several spontaneous groups to read materials and conduct self-generated experiments. Three girls were reading a 
book chapter about light reflection and color vision. They discussed their understanding and each occasionally wrote down key information and related thoughts in a notebook. Then, they approached their teacher to share their findings and questions. The teacher was very excited and called the whole class for a conversation- "Knowledge Building Talk" as the teacher and his students called it.

T: Could we all get together for a KB [Knowledge Building] Talk? S1 just said something that I thought was so amazing. So go ahead.

S1: Well S2 and I had a problem, 'cause we were reading about how white light shines only the true color of the object it bounces off. Well she had a problem. She said: "Well, how does the light know which color to bounce off?” And I thought well maybe we can't see color, maybe we can only see color when light shines on it and bounces off.

S3: Did she write a note about that [in Knowledge Forum]?

T: Not yet. Not yet. But what do you think about that, her theory, that we don't see... So this green board can only appear green if there is light bouncing off. Do you agree with S1?

S4: Yeah, we can only...[several other students talking simultaneously]

[S4 turns off the classroom light.]

S4: Look! Look! You can still see it. [Students observe the green board.]

T: If we covered up, blacked out this room completely.

S4: It would be grey, black and white. I mean...

S5: Yeah, because no light can get in here and you can't see anything.

S4: Yeah, because you need light to see. Yeah, it would be grey and black.

T: So do we need light to see? And what about to see color? 
S1: Yeah, you need light to see, except for black.

T: That's really interesting.

In the above episode, the teacher listened to student ideas and captured promising ideas as objects of emergent knowledge-building discourse. He invited student input (e.g., what do you think about...her theory?), asked thought-provoking questions to facilitate student reasoning (e.g., do we need light to see? And what about to see color?), and expressed intellectual enthusiasm and interest (e.g., that's really interesting). The students recommended this important idea to be recorded in Knowledge Forum, which gives ideas an objectified public representation. They conducted improvisational on-site experiments (e.g., turn off the classroom light and observe the green board) to test the idea and collaboratively interpreted the results, leading to important insights in the connections among a number of concepts: reflection and absorption, colors of light, vision, and color vision. The above inquiry event further triggered subsequent discussions and investigations.

Beyond the discourse occurring during and right after the reading of a material, the students engaged in sustained, progressive discourse — online and offline - in which concepts, ideas, and language obtained from reading materials were continually revisited and used to advance their understanding. In the discourse in Knowledge Forum, the students wrote a total of 168 notes (in addition to the 66 individual portfolio notes), among which the scaffold "New information," for labeling new information from reading, was used by 20 of the 22 students for a total of 63 times. In the notes involving "New information," the authors identified the focal problems the new information addressed and further reasoned out new ideas (often labeled as "My theory") and questions (often labeled as "I need to understand") in light of the new information. There were 12 notes explicitly combining the scaffold "New information" 
with "I need to understand" and 8 combining "New information" with "My theory." These results show that the students' writing was not simply telling and sharing what they had learned from the readings, but transforming their knowledge for deeper explanations and understanding (Bereiter \& Scardamalia, 1987; Sun et al., 2010). Information and ideas contributed in Knowledge Forum were constantly referred to and built upon by peers in the subsequent online and face-to-face discourse. As a specific example, in the Knowledge Forum view called "Where Light Goes and How," a conceptual thread of discourse focused on how light travels through certain materials, extended over three weeks (see Figure 3 for selective entries).

Insert Figure 3 about here

The discourse on how light travels through certain materials began with CF's note about an incidental observation indicating that light can go through some materials but not others, attempting to understand how these materials are different, and why. Among the follow-up contributions, SG introduced new information from a reading and explicitly identified the two types of materials as "transparent" and "opaque." RP's note, also involving "New information" from reading, further elaborated transparent and opaque materials and additionally introduced translucent materials, followed by GM's note that gave an explicit definition of each. Thus, these concepts were not merely treated as definitions for the students to comprehend and share, but became language tools and thinking devices (Wertsch, 1998) that the students could use to explicate and formalize their thinking and leverage deepening discourse. Chains of progressive problems were raised and discussed connecting up related 
knowledge themes, such as: Why can light go through thick glass but not thin tin foil? How do colors of materials affect whether light can go through? Why does transparent water reflect light since light can go through it? The above online discussions extended into further classroom discussions and experiments.

To foster productive use of reading for sustained knowledge-building discourse, the teacher encouraged his students to generate problems of understanding and contribute ideas early on before they engaged in reading. He engaged his students in epistemic discussions about proper attitudes toward books, avoiding seeing books as the end answers. When introducing reading materials and co-reading with the students, he modeled connecting reading to students' questions and ideas that had emerged from the classroom work and online discussions (e.g., I'm interested in what X said earlier about...). In classroom discussions and inquiry activities, he made connections to what the students had read earlier to promote transfer and conceptual advancement, with the students constantly making similar connections.

\section{$\underline{\text { Reading as Dialogues between Local Understanding and Knowledge Out in the World }}$}

Student engagement in thinking and discoursing with reading further enabled reflective dialogues between the local understanding of the student community and knowledge in the larger world, such as that produced by the scientist communities and by peer classrooms with which the students had a chance to interact. Before the Grade 4 light inquiry, a class of Grade 5/6 students at the same school had investigated seasons using Knowledge Forum. Their work on seasons involved observing and analyzing changes of shadows in relation to the position of the sun. With the consent of the Grade 5/6 students, the Grade 4 students in this study read their discussions in Knowledge Forum and built on their work to investigate how shadows are 
made and why shadows change in size. As the students read prior work of peer classrooms and professional text about research and concepts in optics, they reflected on their own ideas and understanding and monitored conceptual consistency and tensions. Consistent theories and observations from the outside communities were summarized and used by the students to support and extend their ideas. Inconsistencies were identified stimulating the need of further idea development. For example, the light inquiry led the students to the understanding of white light being a mixture of different colors. Then, they wondered why human eyes cannot see the colors "hidden" in white light. A student came up with a theory that caught her peers' interest, hypothesizing that this is because light travels too fast so that the colors can only be seen when the light is slowed down somehow. She then read Newton's work in optics, which partially supports the above idea but also poses a conceptual challenge, as she indicated in the following note (Figure 4). Conceptual dialogues as such created productive opportunities for deep understanding and continual idea advancement.

Insert Figure 4 about here

\section{Discussion}

The present study investigates reading practice in an elementary science classroom that implements the knowledge building pedagogy and technology (Scardamalia \& Bereiter, 2006). The tracing of student conversations in Knowledge Forum and the content analysis of their individual portfolio notes demonstrated productive knowledge advancement achieved by the community. Among other classroom processes enabling the collaborative productivity 
(see Zhang \& Messina, 2010 for the compressive analyses), the students' deep engagement in reading became an essential means to sustained and collaborative idea advancement. The qualitative analysis of the classroom videos, discourse records, and teacher reflections helped to characterize the reading practice along four dimensions that appear to be inextricably connected: reading for the purpose of advancing community knowledge; as progressive problem solving; embedded in sustained knowledge-building discourse; and as dialogues between local understanding and knowledge in the larger world. Drawing on the data analysis, the discussion section elaborates the classroom processes of reading for collaborative idea advancement along with the teacher's role in these processes.

Elaborating the Practice of Reading in a Knowledge Building Community

Earlier studies on reading in content areas primarily focused on reading for comprehending and interpreting information from text and other media. The latest literature additionally highlights peer interaction surrounding text to construct and share knowledge (Cervetti et al., 2006; Guthrie, 2004; Palincsar \& Magnusson, 2001) and engaging students in inquiry-oriented reading in line with how reading is approached in real world knowledge communities (Phillips \& Norris, 2009). This study contributes to elaborating reading for collaborative idea advancement in an elementary knowledge building community drawing on rich and extended data collection. Different from many programs to integrate reading with disciplinary inquiry (e.g., Perencevich, 2004), the knowledge building community framework engages students in collaborative efforts to advance community knowledge beyond individual learning. Students take on high-level responsibility for goal setting, long-term planning, and improvisational process control instead of following through predefined scripts for searching and integrating information. Reading for collaborative idea advancement in this context 
involves constructive comprehension of text and peer sharing and further requires deeper epistemic and social engagement. Comprehending, integrating, and sharing information from text is neither the beginning nor the end of inquiry, but integral to sustained creative practices that are centered on collective and continual advancement of knowledge.

In a knowledge building community, reading is not only a means to enriching individual knowledge and answering personal questions, but becomes a community action to address gaps and challenges in the community's knowledge space (Scardamalia et al., 1994) that represents the shared, evolving history of ideas. Taking collective responsibility for advancing the community's knowledge requires a much deeper epistemic engagement of students than being an independent, self-regulated reader, which represents a common pursuit of most recent reading programs (Palincsar, 2003). In addition to monitoring and regulating their comprehension of the text, students need to reflect on how the information from the text may contribute to addressing their collective knowledge goals, in what ways the information supports or challenges existing ideas in their community space, what pieces of information are still missing and what deeper problems and challenges lie ahead, for themselves and for the community as a whole.

Reading, thus, becomes a sustained process of progressive problem solving. This process is consistent with the perspective of reading as active reasoning, problem solving, and inquiry in general (Anderson, 1984; Thorndike, 1917; Phillips \& Norris, 2009); but it involves much deeper and more transformative operations at both the individual and community levels. The learners in this study not only detected and addressed information gaps and problems directly hindering their comprehension of the text (e.g., understanding unfamiliar words); they continually drew upon what they had understood to identify deeper problems of 
understanding that required conceptual inquiry beyond the text per se (e.g., why does the rod only look bent when observed from a certain angle? why are rainbow colors always in the same order?). To address such problems, the students spontaneously designed, conducted, and discussed experiments often side by side with their re-reading of text, enabling the interplay between firsthand and text-based investigations (Palincsar \& Magnusson, 2001). As Kuipers (1994) said: "Both commonsense and expert knowledge are always incomplete. No one understands down to the last detail how any mechanism actually works." (p. 1) Textbooks and other materials only present partial knowledge. Students as knowledge builders need to engage in progressive problem finding and solving to identify important information that is missing and engage in sustained deepening understanding drawing on the text. Such efforts of problem solving and knowledge extrapolation have been identified as indicators of constructive learning from text at an individual level through thinking protocol analysis (Chan, Burtis, Scardamalia, \& Bereiter, 1992). The current study further elaborates such constructive processes in an authentic classroom context of collaborative and sustained knowledge building that extended over multiple months. The students endorsed progressive problem solving and knowledge extrapolation as a collaborative and continuous effort, which helped them to better understand and re-contextualize what the text presented (e.g., the light bending example), co-construct cross-theme connections beyond the text, and identify and work on increasingly sophisticated ideas and problems. Student ideas and sustained idea advancement, not the text or other authoritative sources, came to the center of the stage. Progressive problem solving lies at the heart of creative and adaptive expertise (Bereiter, 2002; Hatano \& Inagaki, 1986). Engaging in progressive problem solving with text helps 
students to develop such expertise and learn how to make creative contributions to an everadvancing knowledge enterprise.

This process of progressive inquiry and idea improvement further gives rise to and gains support from sustained knowledge-building discourse, both in the classroom and online. Students engage in cooperative reading to co-analyze and understand difficult text and connect the new information to the focal problems and ongoing inquiry work of the community. Important reading information and ideas generated are then shared and further examined, interpreted, re-conceptualized, and built upon to enable further idea development. Deeper issues are collectively identified and discussed leading to the formulation of deeper inquiry goals. Key concepts and terms obtained from readings are constantly referred to in the subsequent discourse and used by students as tools to formalize, clarify, expand, and advance their understanding.

Reading professional text and knowledge building work from peer classrooms further enables reflective dialogues between local understanding and knowledge out in the world. Such dialogues help to connect students to the larger networks of knowledge communities that may provide intellectual resources, stimulation, and discourse and inscription tools in a specific domain area. Consistent ideas and information are utilized to support, enrich, and extend student current understanding; conceptual inconsistencies are reflected upon informing deeper examination and exploration of ideas.

\section{Pedagogical Design and the Teacher's Role}

The pedagogical designs implemented in this study focused on enhancing students' epistemic agency to formulate deepening inquiry and collective responsibility for sustained advancement of community knowledge (Scardamalia, 2002). To this end, an opportunistic 
collaboration and participatory structure was adopted to encourage co-planning and coadjustment of knowledge building processes (Zhang et al., 2009), supported by the adjustable and interconnected online knowledge spaces and interaction tools in Knowledge Forum. The teacher engaged in the process as a co-knowledge builder to leverage and catalyze community interactions (e.g. building-on, challenging, connecting, reviewing of ideas) by which the community could sustain itself for productive knowledge building (see Zhang \& Messina, 2010 for comprehensive analysis of the teacher's role). He engaged in deep listening to and reading of student ideas, highlighted important historical connections of ideas in the community, co-formulated deepening knowledge goals and deeper inquiries with his students. Specifically pertaining to reading, he introduced new readings by reviewing student-identified challenges, questions, and related ideas; provoked student initial questions, ideas, and discussions before they read the material; consulted student interest to formulate spontaneous reading groups; participated in the small groups to co-analyze and highlight key information from text, model various reading strategies and help students who were challenging readers. In all contexts, such as experiments and discussions, he helped the students to realize connections between their current work and what they had read earlier, so as to enable productive use of text as thinking device (Wertsch, 1998).

Knowledge Forum integral to the above pedagogical designs played a critical role in enabling productive reading along with the collaborative knowledge building practice, as a whole. It provided a communal online knowledge space that gave student ideas—and, thus, their community knowledge - a public and objectified representation, transcending the boundaries of time (e.g., grades 1 to 4), grouping structures (different small groups, classrooms), and activity contexts (e.g., reading, experiment, discussion). The online 
interaction tools (e.g., build-on, rise-above) and scaffolds (e.g., My theory, New information, I need to understand) further encouraged progressive examination, refinement, and reconceptualization of ideas as explicit objects of community discourse. The students recorded their ideas, problems of understanding, key information from reading, and empirical works in Knowledge Forum as discourse entries. They did so in much the same way as how students created notebook entries in the study of Palincsar and Magnusson (2001), but in a public form in a shared and accumulative database. As a result, the entries were instantly shared with peers and further built upon and referred to in the subsequent inquiry and discussions, enabling sustained investigation and accumulative advancement of ideas. With the students' contributions and advancements evident in the evolving online knowledge space, the need to organize presentations and teach/share with peers as a culminating task-a common design used in the reading and inquiry programs reviewed in the beginning of this article—was minimized.

\section{Conclusions}

Reading for collaborative advancement of ideas represents an important competency that is needed for engaging in creative knowledge practices in the $21^{\text {st }}$ century. The present study contributes to elaborating classroom processes and instructional support by which students can engage in such reading practice as a part of their disciplinary knowledge building. Along with our previous work (Sun et al., 2010), this study suggests that high-level literacy—productive reading and writing, sophisticated vocabulary, visual representation of ideas - integral to creative and collaborative knowledge practices can be developed as early as from primary grades, co-advancing with basic literacy skills and disciplinary learning. 
Reading in science and other content areas tends to focus on understanding isolated terms and factual information and often lacks idea-centered reasoning and discourse (Phillips \& Norris, 2009). In enhanced programs and high-performing science classrooms, we may see certain signs of the four aspects of reading elaborated in this study such as contributive interpretation and discussion of text. Examining the knowledge building community supported by Knowledge Forum provided a unique opportunity to observe such reading practice in depth through extensive data collection. The four facets of reading for idea advancement characterize reading integral to the unfolding intellectual history of a community in support of its continuous effort for deepening understanding and advancing knowledge in a domain area. Reading in the moment of the reader interacting with the text involve active inquiry and processing; The epistemic level and scope of such inquiry is substantially increased when student reading is embedded in a dynamic social context of student-driven knowledge building and creation, stimulated by and contributing to students' continual idea advancement over multiple weeks, months, or even years. The four interrelated facets of reading elaborated in this article can be used to guide classroom designs to enable student productive use of text and other sources for knowledge building in science and potentially other content areas, employing the specific teacher support strategies elaborated in the results. To enabled productive reading for idea advancement, emerging programs to build connections between literacy and disciplinary inquiry needs to engage students in advancing communal, collective knowledge through sustained problem solving and discourse and move beyond a pre-scripted, simplistic model of inquiry. Electronic knowledge spaces and interaction tools designed in light of principles of collaborative learning and knowledge building may provide strong support for both content inquiry and literacy practice. 
Although the content analysis of the students' portfolio notes indicated individual progress in content understanding, the analysis of reading focused on the classroom processes as a whole and did not trace individual performance and change. Fortunately, our recent longitudinal study (Sun et al., 2010) focusing on a previous student cohort taught by the same teacher provided this sort of data. The analyses revealed the growing use and diffusion of sophisticated vocabulary and concepts in student online discourse, which was positively correlated with the individuals' literacy tests and scientific understanding. Future work needs to further elaborate reading for idea advancement among students of different grade levels and in various content areas; and investigate specific pedagogical design issues (e.g., textbook, technological support, assessment) to engage students in productive reading and writing in support of disciplinary knowledge building.

\section{Acknowledgements}

The reported work was supported by the Faculty Research Award Program of the University at Albany. We owe special thanks to the teacher, Richard Messina, and his students at the Institute of Child Study of the University of Toronto for their fascinating work enabling this research. We also extend our thanks to Jane Wilde for her assistance in data analysis and to the anonymous reviewers for their comments and suggestions.

\section{References}

Anderson, R. C. (1984). Role of reader's schema in comprehension, learning, and memory. In R. C. Anderson, J. Osborn, and R. Tierney (Eds.), Learning to read in American schools (pp. 372 - 384). Hillsdale, NJ: Erlbaum. 
Anderson, T. H., West, C. K., Beck, D. P. McDonell, E. S., \& Frisbie, D. S. (1997).

Integrating reading and science education: On developing and evaluating WEE Science. Journal of Curriculum Studies, 29(6), 711-733.

Anderson, T.H., \& Armbruster, B.B. (1984). Content area textbooks. In R.C. Anderson, J. Osborn, \& R.J. Tierney (Eds.), Learning to read in American schools (pp. 193-224). Hillsdale, NJ: Erlbaum.

Applebee, A. N. (1981). Writing in the secondary school. Urbana, IL: National Council of Teachers of English.

Applebee, A. N., Langer, J.A., Nystrand, M., \& Gamoran A. (2003). Discussion-based approaches to developing understanding. American Educational Research Journal, 40 (3), 685-730.

Baker, L. (1991). Metacognition, reading, and science education. In C. M. Santa \& D. E. Alvermann (Ed.), Science learning: Processes and applications (pp. 2-13). Newark, DE: International Reading Association.

Barton, D., \& Hamilton, M. (1998). Local literacies: reading and writing in one community. London: Routledge.

Beck, I. L., McKeown, M. G., Hamilton, R. L., \& Kucan, L. (1997). Questioning the author: An approach for enhancing student engagement with text. Newark, DE: International Reading Association.

Bereiter, C. (2002). Education and mind in the knowledge age. Mahwah, NJ: Erlbaum.

Bereiter, C. \& Scardamalia, M. (1987a). An attainable vision of high literacy: Approaches to teaching higher-order skills in reading and writing. Curriculum Inquiry, 17(1), 9-30. 
Bereiter, C. \& Scardamalia, M. (1987b). The psychology of written composition. Hillsdale, NJ: Erlbaum.

Bereiter, C., \& Scardamalia, M. (2005). Technology and literacies: From print literacy to dialogic literacy. In N. Bascia, A. Cumming, A. Datnow, K. Leithwood, \& D. Livingstone (Eds.), International handbook of educational policy (pp. 749-761). Dordrecht, Netherlands: Springer.

Brown, A. L., \& Campione, J. (1996). Psychological theory and the design of innovative learning environments: On procedures, principles, and systems. In L. Schauble \& R. Glaser (Eds.), Innovations in learning: New environments for education (pp. 289-325). Mahwah, NJ: Erlbaum.

Cantoni-Harvey, G. (1987). Content-area language instruction: Approaches and strategies. Reading, MA: Addison-Wesley.

Cervetti, G. N., Pearson, P. D., Bravo, M. A., \& Barber, J. (2006). Reading and writing in the service of inquiry-based science. In R. Douglas, M. Klentschy, \& K. Worth (Ed.), Linking science and literacy in the K-8 classroom (p. 221-244). Arlington, VA: National Science Teachers Association.

Chan, C. K. K., Burtis, P. J., Scardamalia, M., \& Bereiter, C. (1992). Constructive activity in learning from text. American Educational Research Journal, 29, 97-118.

Chi, M. T. H. (1997). Quantifying qualitative analysis of verbal data: A practical guide.

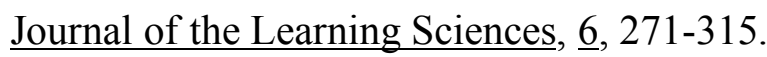

Chi, M. T. H. (1997). Quantifying qualitative analysis of verbal data: A practical guide. Journal of the Learning Sciences, 6, 271-315. 
Chinn, C. A., Anderson, R. C., \& Waggoner, M. (2001). Patterns of discourse in two kinds of literature discussion. Reading Research Quarterly, $\underline{36}$, 378-411.

Collins, A. (1998). Learning communities: A commentary on chapters by Brown, Ellery, and Campione, and by Riel. In J. G. Greeno \& S. V. Goldman (Eds.), Thinking practices in mathematics and science learning (pp. 399-405). Mahwah, NJ: Erlbaum.

Collins, N. D. (1994). Metacognition and reading to learn. ERIC Clearinghouse on Reading, English, and Communication Digest \#96.

Connolly, P., \& Vilardi, T. (1989). Writing to learn mathematics and science. New York: Teachers College Press.

Csikszentmihalyi, M. (1999). Implications of a systems perspective for the study of creativity. In R.J. Sternberg (Ed.), Handbook of creativity (pp. 313-335). Cambridge, UK: Cambridge University Press.

Denise, M. K. (1987). Structure strategies for comprehending expository text. Reading Research and Instruction, 27, 66-72.

Dunbar, K. (1997). How scientists think: Online creativity and conceptual change in science. In T. B. Ward, S. M. Smith \& S. Vaid (Eds.), Conceptual structures and processes: Emergence, discovery and change (pp. 461-493). Washington, DC: APA Press.

Ebbers, M., \& Rowell, P. (2002). Description is not enough: Scaffolding children's explanation. Primary Science Review, 74, 10-13.

Geisler, C. (1994). Academic literacy and the nature of expertise: Reading, writing, and knowing in academic philosophy. Hillsdale, NJ: Erlbaum. 
Goldman, S. (1997). Learning from text: Reflections on the past and suggestions for the future. Discourse Processes, 23, 357-398.

Graesser, A.C. (2007). An introduction to strategic reading comprehension. In D. McNamara (Ed.), Theories of text comprehension: The importance of reading strategies to theoretical foundations of reading comprehension (pp. 3-26). Mahwah, NJ: Erlbaum.

Guthrie, J. T. (2004). Classroom contexts for engaged reading: An overview. In J. T. Guthrie, A. Wigfield, \& K. C. Perencevich (Eds.) Motivating reading comprehension: Conceptoriented reading instruction (pp. 1-24). Mahwah, NJ: Erlbaum.

Hatano, G., \& Inagaki, K. (1986). Two courses of expertise. In H. Stevenson, H. Azuma, \& K. Hakuta (Eds.), Child development and education in Japan (pp. 262-272). New York: W. H. Freeman and Company.

Kiewra, K. A., DuBois, N. F., Christensen, M., Kim, S., \& Lindberg, N. (1989). A more equitable account of the note taking functions in learning from lecture and from text. Instructional Science, $\underline{18(3), 217-232}$

Krajcik, J., Blumenfeld, P. C., Marx, R. W., Bass, K. M., \& Fredricks, J. (1998). Inquiry in project-based science classrooms. Journal of the Learning Sciences, $\underline{7}(3 / 4), 313-350$.

Kuipers, B. (1994). Qualitative reasoning: Modeling and simulation with incomplete knowledge. Cambridge, Mass.: MIT Press

Lankshear, C., \& Knobel, M. (2003). New technologies in early childhood literacy research: A review of research. Journal of Early Childhood Literacy, $\underline{3}(1), 59-82$.

Latour, B., \& Woolgar, S. (1979). Laboratory life: The social construction of scientific facts. Newbury Park, CA: Sage.

Lemke, J. (2000). Across the scales of time: Artifacts, activities, and meanings in ecosocial 
systems. Mind, Culture, and Activity, ㄱ, 273-290.

Newton, D. P., \& Newton, L. D. (2000). Do teachers support causal understanding through their discourse when teaching primary science? British Educational Research Journal, $\underline{26}, 599-613$.

Nonaka, I., \& Takeuchi, H. (1995). The knowledge-creating company. Oxford, UK: Oxford University Press,.

Nystrand, M. (1997). Opening dialogue: Understanding the dynamics of language and learning in the English classroom. New York: Teachers College Press.

Olson, D.R. (1997). Talking about text and culture of literacy. In B. Davis \& D. Corson (Eds.), Oral discourse and education (pp.1-9). Boston, MA: Kluwer.

Padilla, M.J., Muth, K.D., \& Padilla, R.K. (1991). Science and reading: Many process skills in common? In C.M. Santa \& D.E. Alvermann (Ed.), Science learning: Processes and applications (pp. 14-19). Newark, Delaware: International Reading Association.

Palincsar, A. S. \& Ladewski, B. (2006). Literacy and the learning sciences. In K. Sawyer (Ed.), Handbook of the Learning Sciences (pp. 299-317). New York: Cambridge University Press.

Palincsar, A. S. (2003). Collaborative approaches to reading comprehension. In A. Sweet \& C. Snow (Eds.). Rethinking reading comprehension (pp. 99-115). New York: Guilford Press.

Palincsar, A. S., \& Brown, A. L. (1984). Reciprocal reaching of comprehension-fostering and comprehension-monitoring activities. Cognition and Instruction, $1,117-175$.

Palincsar, A. S., \& Magnusson, S. J. (2001). The interplay of firsthand and text-based investigations to model and support the development of scientific knowledge and 
reasoning. In S. Carver \& D. Klahr (Eds.), Cognition and instruction: Twenty-five years of progress (pp.151-194). Mahwah, NJ: Erlbaum.

Perencevich, K.C. (2004). How the CORI Framework looks in the classroom. In J. T. Guthrie, A. Wigfield, \& K. C. Perencevich (Eds.) Motivating reading comprehension: Conceptoriented reading instruction (pp. 25-53). Mahwah, NJ: Erlbaum.

Phillips, L. M., \& Norris, S. P. (1999). Interpreting popular reports of science: What happens when the reader's world meets the world on paper? International Journal of Science Education, 21, 317-327.

Phillips, L. M., \& Norris, S. P. (2009). Bridging the gap between the language of science and the language of school science through the use of adapted primary literature. Research in Science Education, $\underline{39}, 313-319$.

Salmon, W. C. (1984). Scientific explanations and the causal structure of the world.

Princeton, NJ: Princeton University Press.

Salmon, W. C. (1984). Scientific explanations and the causal structure of the world. Princeton, NJ: Princeton University Press.

Sawyer, R. K. (2006). Analyzing collaborative discourse. In R. K. Sawyer (Ed.), Cambridge Handbook of the Learning Sciences (pp. 187-204). New York: Cambridge University Press.

Sawyer, R.K. (2007). Group genius: The creative power of collaboration. New York: Basic Books.

Scardamalia, M. (2002). Collective cognitive responsibility for the advancement of knowledge. In B. Smith (Eds.), Liberal education in a knowledge society (pp. 67-98). Chicago, IL: Open Court. 
Scardamalia, M., \& Bereiter, C. (2006). Knowledge building: Theory, pedagogy, and technology. In R. K. Sawyer (Eds.), Cambridge Handbook of the Learning Sciences (pp. 97-115). New York: Cambridge University Press.

Scardamalia, M., Bereiter, C., Brett, C., Burtis, P.J., Calhoun, C., \& Smith Lea, N. (1992). Educational applications of a networked communal database. Interactive Learning Environments, 2(1), 45-71.

Scardamalia, M., Bereiter, C., Hewitt, J., \& Webb, J. (1996). Constructive learning from texts in biology. In K. Fischer \& M. Kirby (Eds.), Relations and biology learning: The acquisition and use of knowledge structures in biology (pp. 44-64). Berlin: SpringerVerlag.

Simonton, D.K. (2003). Scientific creativity as constrained stochastic behavior: The integration of product, person, and process perspectives. Psychological Bulletin, $\underline{129}$, $475-494$.

Stahl, G. (2006). Group cognition: Computer support for building collaborative knowledge. Cambridge, MA: MIT Press.

Strauss, A., \& Corbin, J. (1998). Basics of qualitative research: Techniques and procedures for developing grounded theory (2nd ed). Newbury Park, CA: Sage.

Sun, Y., Zhang, J., \& Scardamalia, M. (2010). Knowledge building and vocabulary growth over two years, Grades 3 and 4. Instructional Science, $\underline{38}, 247-271$.

Tenopir, C., \& King, D. W. (2004). Communication patterns of engineers. New York: John Wiley \& Sons.

Tenopir, C., \& King, D. W. (2004). Communication patterns of engineers. New York: John Wiley \& Sons. 
Thorndike, E.L. (1917). Reading as reasoning. Journal of Educational Psychology, $\underline{8}$, 323332.

Vitale, M. R., \& Romance, N. R. (2007). A knowledge-based framework for unifying contentarea reading comprehension and reading comprehension strategies. In McNamara, D. S. (Ed.), Reading comprehension strategies: Theory, interventions, and technologies (pp.73-104). Mahwah, NJ: Erlbaum.

Wertsch, J. V. (1998). Mind as action. New York: Oxford University Press.

Wittrock M. C. (1991). Generative teaching of comprehension. The Elementary School Journal, 92(2), 169-184.

Wixson, K. K., \& Peters, C. W. (1984). Reading redefined: A Michigan Reading Association position paper. Michigan Reading Journal, 17, 4-7.

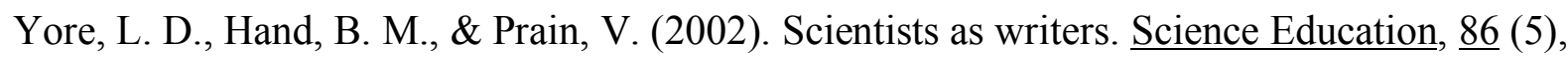
$672-692$.

Yore, L. D., Hand, B. M., Goldman, S. R., Hildebrand, G. M., Osborne, J. F., et al. (2004). New directions in language and science education research. Reading Research Quarterly, $\underline{39}(3), 347-352$.

Zhang, J., \& Messina, R. (2010). Collaborative productivity as self-sustaining processes in a Grade 4 knowledge building community. Proceeding of the 9th International Conference of the Learning Sciences (ICLS 2010). International Society of the Learning Sciences.

Zhang, J., Scardamalia, M., Reeve, R., \& Messina, R. (2009). Designs for collective cognitive responsibility in knowledge building communities. Journal of the Learning Sciences, $\underline{18}$, $7-44$. 
Figures

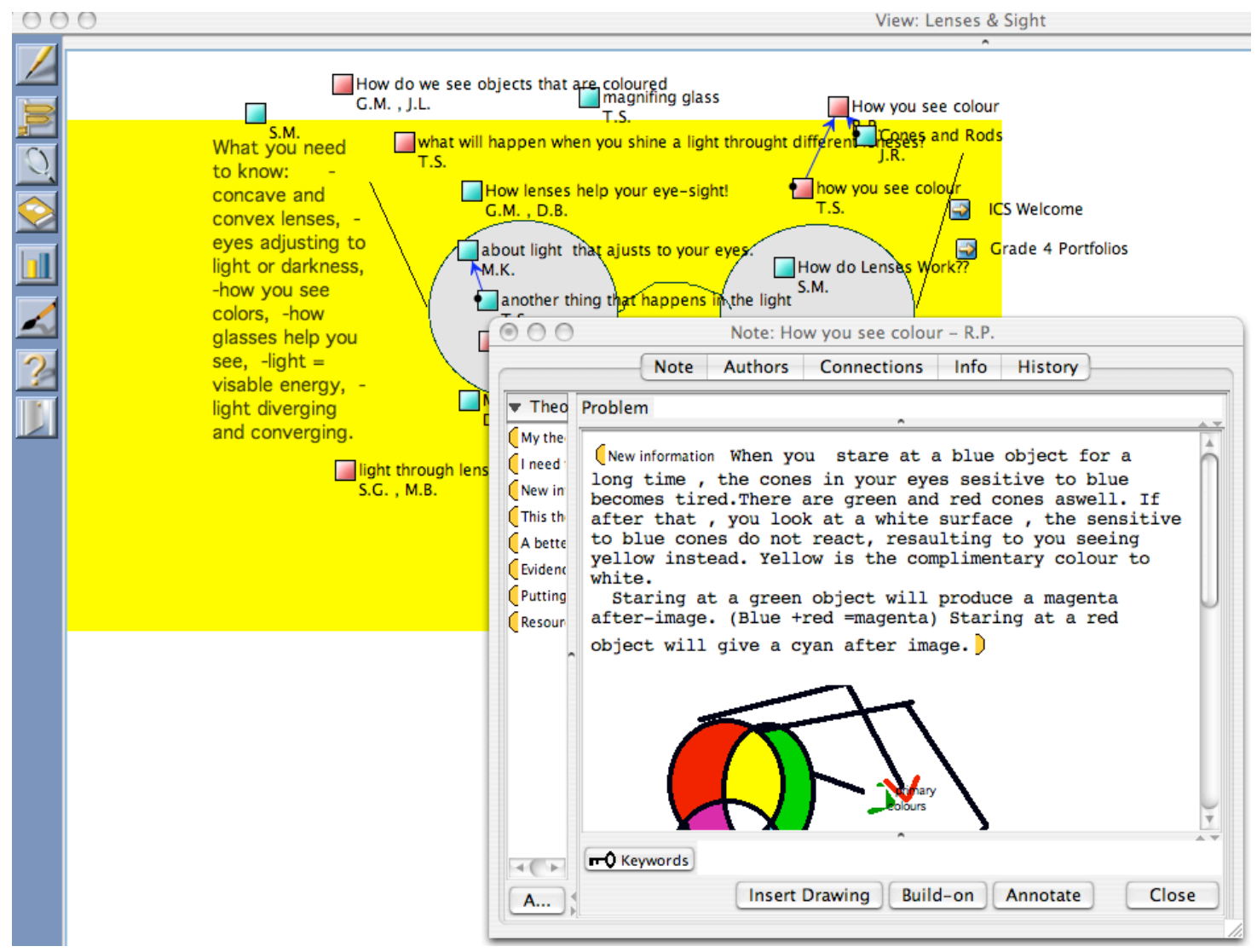

Figure 1. Student discourse in the Lenses and Sight view in Knowledge Forum. Each square icon represents a note; a line between two notes indicates a build-on. The opened note, by RP, contributed new information from a reading explaining how we see colors, labeled with the scaffold of "New information." 


\section{Light and plants}

by: LL, CF Last modified: May 16

Problem: How do plant[s] adapt to light?

$<$ New information Green plants capture energy from the sun and use it to make their own

food. And use this food to grow. [P]hotosynthesis energy from sunlight is capture by the chlorophy[11] in plant cells. Energy is then [used] to make food energy from carbon dioxide and water. A plant uses the sugars and oxygen it has made to give it energy to $\mathrm{s}[\mathrm{u}] \mathrm{rvive}$. A plant produces more food then it uses. This excess food is stored in the plants roots, stems, and leaves. When other living things eat plants, they are able to obtain this excess food. $>$

Figure 2. A note co-authored by two students contributing new information from what they had read. " $<$ New information $>$ " is a scaffold in Knowledge Forum, under the scaffold set for theory development. 


\section{Two types of materials for light}

by: CF Last modified: Apr 28

Problem: How does light travel through certain materials?

$<$ My theory: I noticed something happen when $\mathrm{CN}$ left his flashlight on the table. The

light went through a plastic bin and hit a wooden container. I think that light travels through certain materials like light-colored plastic and thin paper but not stuff like tin foil or thick book covers. Light will not go through: wood, dark colored plastic, whole books. Light does go through paper, paper back book covers. I think there are two groups of materials when it comes to light: stuff that light can go through and stuff that light can't. $>$

$<$ I need to understand: why light can go through certain materials even thick ones but not through other materials? >

\section{Why Light can't Travel Through Tinfoil}

by: JR Last modified: May 20

Problem: How does light travel through certain materials?

$<$ My theory: I think light can't go through tinfoil because tinfoil is a reflective material. The light reflects off of the tinfoil like a mirror. >

\section{Opaque and transparent}

by: SG Last modified: May 6

Problem: How does light travel through certain materials?

"I agree with JR light bounces off shiny materials like tin foil. Tin foil acts

like a mirror. Tin foil is solid and so that means light can't travel through 


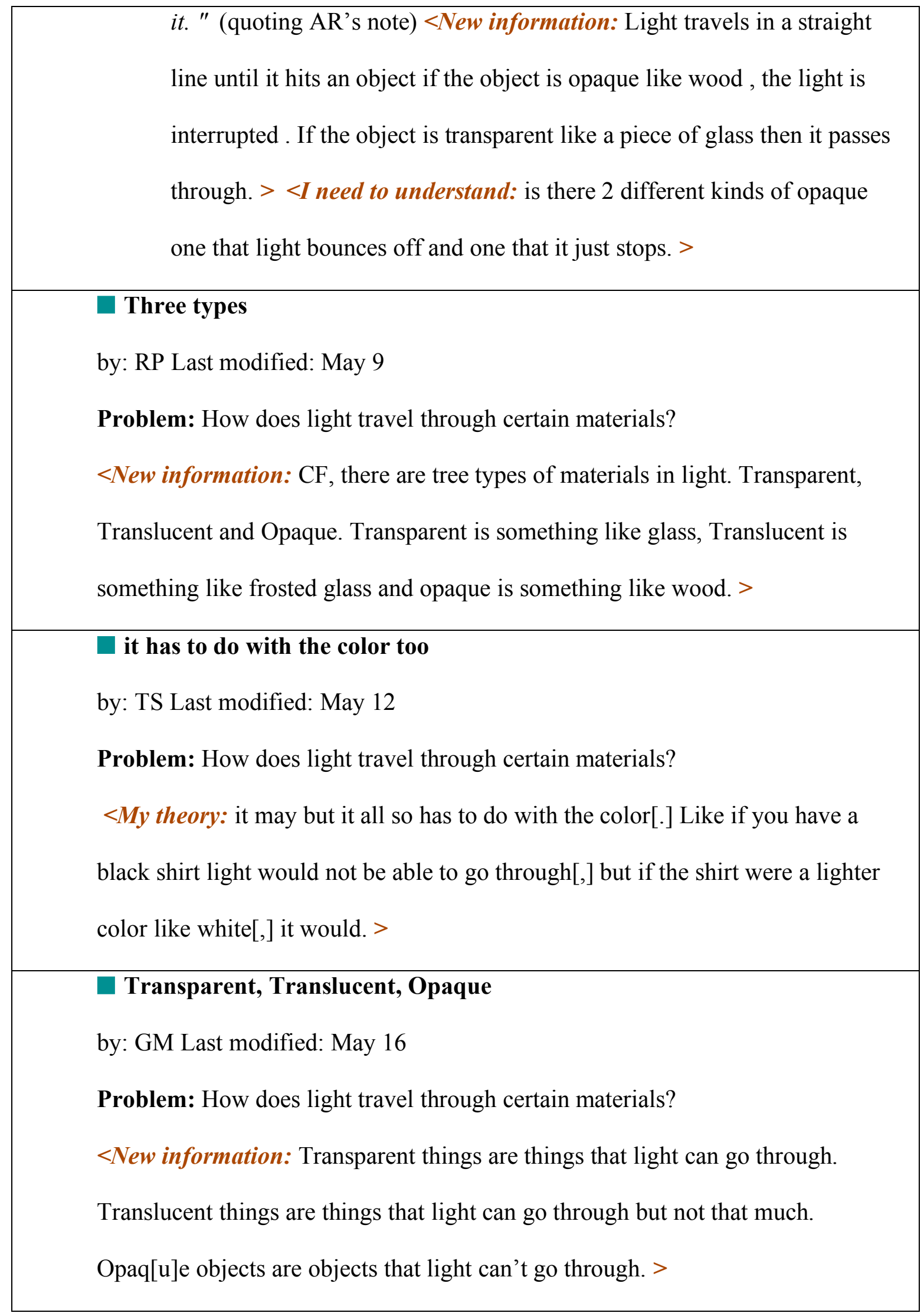




\section{(untitled)}

by: SR Last modified: May 22

Problem: what is transparent, translucent and opaq[u]e?

$<$ Putting our knowledge together: I think water is transparent because light does go through[.] But how does reflection happen? $>$...

Figure 3. A conceptual thread of online discussion focused on how light interact with different materials. Italic words are scaffold labels in Knowledge Forum. An indented note was a buildon note responding to the preceding note. 


\section{LIGHT IS WHITE BECAUSE IT TRAVELS TOO FAST TO SEE}

by: GJ Last modified: May 09

Problem: Why light changes colors when it goes through a prism?

$<$ New information Newton discovered that when you shine light through a prism, the light

changes colors. $>$

$<$ My theory is that light travels too fast to see the colors so it looks white to us but when it goes

through a prism, the prism slows down the light and we are able to see the colors. >

$<$ New information Newton also discovered that if you put another prism after the first prism, the

colored light would become white light again. >

$<$ I need to understand why would the colored light become white again in the second prism? If

light is white when it travels fast and if a prism slows down light, then two prisms should not

make white light? Do you have a theory to explain this? >

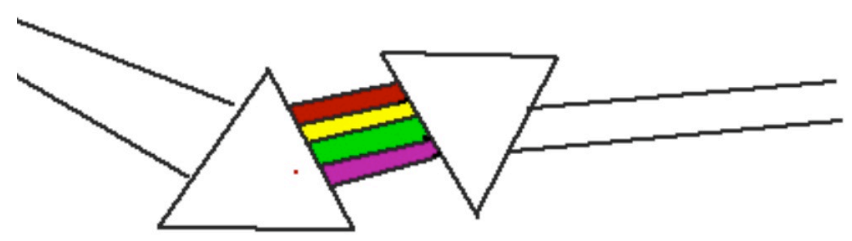

Figure 4. A student's note in Knowledge Forum involving a dialogue between her theory and the work of Newton. Italic words are scaffold labels in Knowledge Forum. 